\title{
IMPROVING THE RELIABILITY OF POWER SUPPLY TO ACTIVE CONSUMERS BY IMPROVING THE TECHNOLOGY FOR MANUFACTURING CABLE PRODUCT
}

\author{
Ivanova Vera Pavlovna ${ }^{1}$, Tsypkina Victoria Vyacheslavovna ${ }^{2 *}$ \\ ${ }^{1}$ Tashkent State Technical University named after I. Karimov, Tashkent, Uzbekistan \\ ${ }^{2}$ Tashkent State Technical University named after I. Karimov, Tashkent, Uzbekistan
}

\begin{abstract}
The growing demand for high-quality transmission of electrical energy with a high level of reliability of cable lines is determined not only by the conditions of operation, installation, but also by the technology of cable production. This article discusses the issues of increasing the reliability of power supply to active consumers, which is achieved through the use of cable products with a higher level of reliability. The concept of "reliability", disclosed in the article, is valid for all cables and wires with insulation, which must maintain integrity as part of the product for the entire period of operation. The use of fundamentally improved technological processes, as the conducted study shows, makes it possible to reduce ohmic resistance of the conductive part of the cable product and thereby allows reducing the temperature parameters of the operating cable line. Cable failure, in most cases, is associated with insulation breakdown, the reason for which can be caused by a rise in temperature inside the cable insulation. In this regard, the creation of conditions for reducing the ohmic resistance of a current-carrying conductor is one of the ways to increase the reliability of a cable product at the stage of its manufacture. Proposed technical solution, considered in this article, is focused on the technological operation - drawing, where changes in the standard drawing route make possible reduction of the ohmic resistance of the current-carrying conductor by $3-5 \%$ for copper and aluminum, respectively.
\end{abstract}

Keywords: drawing, reliability of a cable line, reliability, failure of a cable line, insulation, extrusion, technological operation, conductor, ohmic resistance.

\section{Introduction}

Growing need for high-quality and reliable transmission of electrical energy for the end consumer dictates the use of technical developments with application of new technologies and electrical equipment / electrical appliances, which allow reaching the level of high-tech and robotic enterprises and forming a class of active consumers, focused on the new energy-consuming world $[1,2]$.

At the same time, one of the main places in the process of transmission and distribution of electrical energy belongs to modern technologies that are focused on the use of new generations of power supply systems for the end consumer. These enterprises are complex in composition, being, in general, large life-saving infrastructure systems, capable of supporting: safety, reliability, quality of electricity and services, efficiency, environmental and social acceptability [3].

An analysis of the functional and technological conditions for the use of advanced technologies and equipment, carried out among active consumers, shows that in order to ensure uninterrupted operation, it is necessary to solve new systemic problems that will improve the energy efficiency of the production process as a whole. The use of fundamentally new technical systems will ensure the possibility of reliable and safe power supply, and technological achievements of industrial nature will create conditions for highly efficient transmission of electrical energy with minimal losses [3].

Consumer sector includes integrated power supply systems, which are not always equally adapted to the current operating conditions, which contain different objects by the type of public network [4], which have consumers' outputs to the market of system services and take into account different service life and automation of buildings etc.

At present, the electric power industry is focused on the use of new types of cable and conductor structure, designed for various voltage classes, having high throughput and ensuring strict compliance with modern operational requirements, conditioned by specifics of large cities: high density of construction; reduction of vacant space within the city, associated with the development of infrastructure; high requirements for electromagnetic compatibility of high voltage electrical networks with technical sphere installations and communication networks; permissible levels of impact on humans of electromagnetic fields, created by overhead power lines, etc. [5].

\footnotetext{
* Corresponding author: c-victory@yandex.com
} 
Improving the conductivity of cable lines, taking into account the world experience, can be achieved by replacing existing cable products with new, improved cables with a better design and providing operational reliability in combination with high cable performance.

Based on earlier studies [16, 17, 18], thermal modes of insulation of power cables determine their operational life. Turning to the issue of improving the cable design, the most common way to solve the problem is to regulate the permissible operating temperature of the currentcarrying conductor, which is carried out by making changes in the technological process of manufacturing cable products, which are usually associated with the replacement of technological equipment with a new one, introduction of new cable designs, used structural materials and, accordingly, development of new technology with a complex of certification activities. All this is very time-consuming and entails long and large financial costs.

Thus, cabling and wiring products are one of the most expensive elements of any electric power system, therefore the issue of pricing in its design takes a special place, being a very important economic aspect of choosing the parameters of a cable line.
The tasks of energy saving should be solved already at the design stage of cable lines, taking into account the development of their design, and obtained solutions will allow meeting the requirements for the reliability, safety of cable products and ensuring safety and health of people, involved in installation and subsequent operation of the line [7].

Improving the design of the cable is the process that requires solving difficult and complex production problem, associated with the development of new technology, as well as the design of components and cable fittings for subsequent installation and operation.

At the Department of Electrical Machines of the Tashkent State Technical University, a set of works was carried out to develop and introduce an improved method of drawing into the production process of manufacturing cable and wire products, which increased the throughput of the conductive part of the cable product by reducing the ohmic resistance of the current lead (bus duct). This indicator is achieved by reducing the number of passes along the drawing route and by reducing the degree of deformation fractionality $[8,9]$.

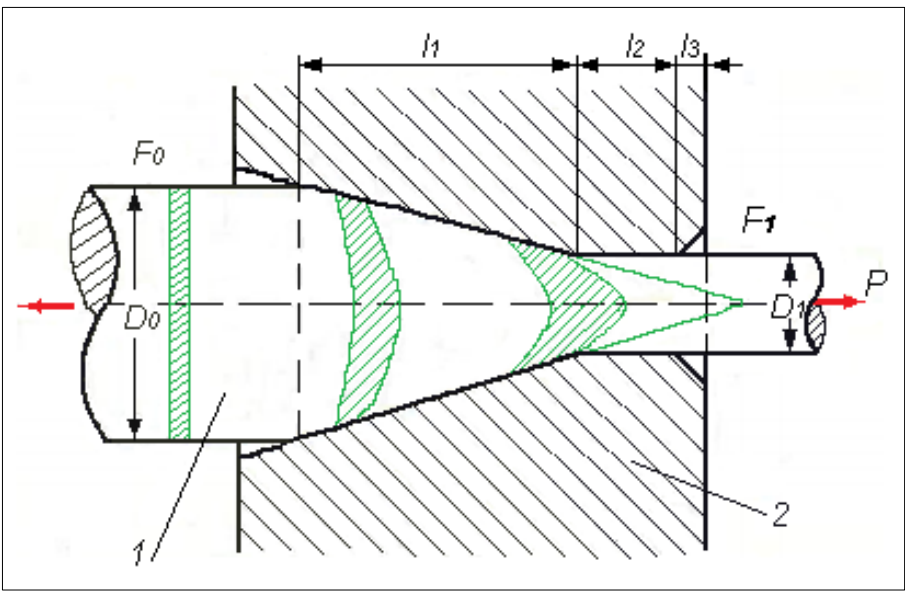

Fig. 1. - Scheme of metal deformation when drawing a solid round profile in a die [9] where, 1- wire; 2-die.

The parameters of the conductive core (CC) are largely determined by the observance of high quality of the initial workpiece (wire rod): "purity" of the chemical composition of copper or aluminum, oxygen content, and absence of metallurgical defects, etc. The quality of the drawn wire is greatly influenced by the observance of the technology, during which the action of contact friction forces is observed on the surface of "metal-wire" section, the direction of which is opposite to the direction of metal movement $[9,10,11,12]$. Impact of the applied external drawing force on the drawn wire (Figure 1) is observed $\left(\mathrm{P}_{\mathrm{z}}\right)$, due to which the elements of the metal structure (grains) are elongated in the axial direction and thinned both in the tangential and in the radial directions under the action of the transverse force Q - internal force (fig. 1) [9, 20, 21].

The impact of external friction forces, caused by the drawing force $\left(\mathrm{P}_{\mathrm{z}}\right)$ in the deformation zone of the technological tool on the contact surfaces causes additional shear stress and, accordingly, additional shear deformation of the inner layers of the metal due to the influence of cold plastic deformation, which affects the main properties of the drawn product - $\mathrm{CC}$ : change in electrical (increase in ohmic resistance) and mechanical (deterioration of plasticity, increase in rigidity) properties of the substance $[9,13]$.

The presence of drawing forces leads to a change in the microstructure of the drawn wire [9], compressing it (fig. 2). 


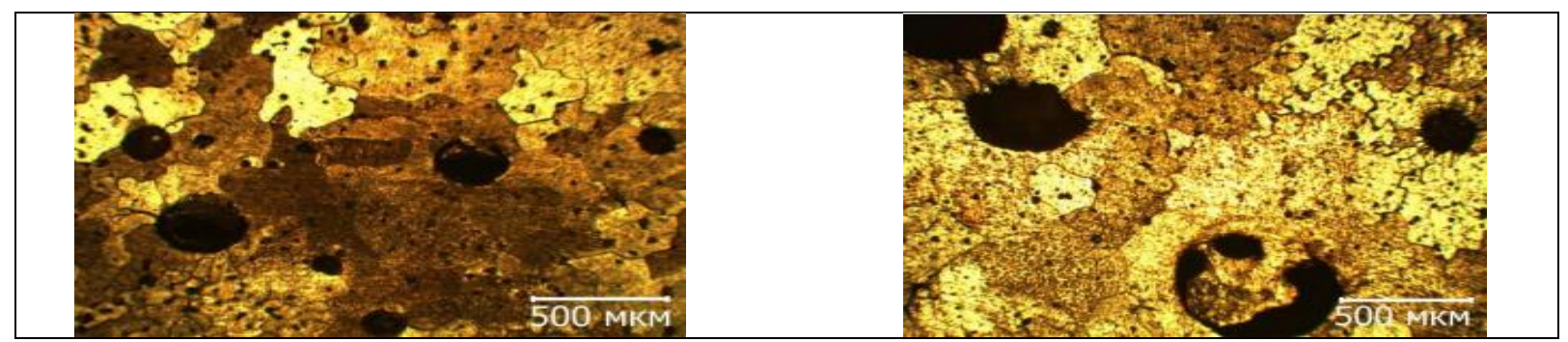

Fig.2 - Microstructure of the prototype copper wire with inclusion, samples are obtained as a result of the experiment, carried out at FE «NAVOI CABLE CONNECTOR» LLC [9].

Thus, as a result of the drawing process (Fig. 1), various types of deformations appear in the processed object (CC), action of which leads ultimately to a proportional change (decrease) in the cross section of the object being drawn and, as a consequence, a change in its microstructure, which is a negative fact, since it worsens the properties of the drawn metal - change in electrical and mechanical parameters, namely, increase in ohmic resistance and increase in stiffness [9, 14, 20, 21]. Cold plastic deformation (drawing) in drawn wire is accompanied by a change in the metal microstructure, as a result of which grains, randomly oriented before deformation, acquire an ordered orientation, striving to be located along the line of action of the applied external force $\left(\mathrm{P}_{\mathrm{z}}\right)[9,14]$. In order to restore necessary electrical and mechanical properties, lost as a result of the action of cold plastic deformation, the drawn wire is heated (annealed) to a certain temperature to restore equilibrium metal structure in order to restructure it.

Analysis of the technical literature led to the conclusion: with an increase in the total degree of deformation $\varepsilon$ during drawing up to $25-30 \%$, the strength characteristics of copper increase rapidly, which leads to an increase in ohmic resistance [9].

From the results of experimental studies (Table 1) of the selected samples, it can be seen that with a decrease in the wire diameter, the ohmic resistance of the sample increases, which is inextricably linked with an increase in the number of passes along the standard drawing route, i.e. an increase in the deformation fractionality of the grain structure of copper $[9,13,15]$.

Table 1. The results of measurements of CC ohmic resistance [9].

\begin{tabular}{|c|c|c|c|c|}
\hline Diameter, mm & Section, $\mathrm{mm}^{2}$ & $\begin{array}{c}\text { Number of passes along } \\
\text { the route, piece }\end{array}$ & $\begin{array}{c}\text { Resistance } \\
1 \mathrm{~m} \text { at } 20^{\circ} \mathrm{C}, \mathrm{Ohm}\end{array}$ & $\begin{array}{l}\text { Length per } 1 \\
\mathrm{Ohm} / \mathrm{m}\end{array}$ \\
\hline 1 & 2 & 3 & 4 & 5 \\
\hline 0,47 & 0,1735 & 13 & 0,101 & 9,9 \\
\hline 0,49 & 0,1885 & 13 & 0,0931 & 10,75 \\
\hline 0,51 & 0,2043 & 13 & 0,0859 & 11,67 \\
\hline 0,55 & 0,2376 & 13 & 0,0739 & 13,55 \\
\hline 0,59 & 0,2734 & 10 & 0,0643 & 15,55 \\
\hline 0,64 & 0,3217 & 10 & 0,0546 & 18,32 \\
\hline 0,69 & 0,3739 & 10 & 0,0469 & 21,33 \\
\hline 0,74 & 0,4301 & 9 & 0,0408 & 24,5 \\
\hline 0,8 & 0,5027 & 9 & 0,0349 & 27,7 \\
\hline 0,86 & 0,5809 & 9 & 0,0302 & 33,15 \\
\hline 0,93 & 0,6793 & 9 & 0,0258 & 38,18 \\
\hline 1 & 0,7854 & 9 & 0,0224 & 44,7 \\
\hline 1,08 & 0,9161 & 9 & 0,0192 & 52,2 \\
\hline 1,16 & 1,0568 & 8 & 0,0166 & 60,25 \\
\hline 1,2 & 1,131 & 8 & 0,0155 & 64,5 \\
\hline 1,25 & 1,2272 & 8 & 0,0143 & 70 \\
\hline 1,35 & 1,4314 & 8 & 0,0122 & 82 \\
\hline 1,45 & 1,6513 & 7 & 0,0106 & 94,5 \\
\hline 1,56 & 1,9113 & 7 & 0,0092 & 108,8 \\
\hline 1,68 & 2,2167 & 7 & 0,0079 & 126,6 \\
\hline
\end{tabular}




\begin{tabular}{|c|c|c|c|c|}
\hline Diameter, $\mathbf{m m}$ & Section, $\mathbf{m m}^{\mathbf{2}}$ & $\begin{array}{c}\text { Number of passes along } \\
\text { the route, piece }\end{array}$ & $\begin{array}{c}\text { Resistance } \\
\mathbf{1} \mathbf{~} \text { at 20 } \mathbf{C}, \mathbf{O h m}\end{array}$ & $\begin{array}{c}\text { Length per 1 } \\
\text { Ohm/m }\end{array}$ \\
\hline 1 & 2 & 3 & 4 & 5 \\
\hline 1,81 & 2,573 & 7 & 0,0068 & 147,7 \\
\hline 1,95 & 2,9855 & 6 & 0,0059 & 169,5 \\
\hline 2,02 & 3,2047 & 6 & 0,0055 & 182 \\
\hline 2,1 & 3,4637 & 6 & 0,0051 & 227,5 \\
\hline 2,26 & 4,0115 & 6 & 0,0044 & 263,2 \\
\hline 2,44 & 4,6759 & 6 & 0,0038 & \\
\hline
\end{tabular}

Analyzing the work of the straight -through drawing machine (SThDM) drawing route was recalculated, which allowed reducing deformation fractionality, according to the technology, without making changes in the operation of the electromechanical system (EMS) of technological equipment. Scientific studies of the operation of the straight -through DM gave results: on drawing machines (VPTs-3-4-550, VSK-13M, MSM$85)$, the result of improved quality indicators of copper wire samples by $5 \%$ was achieved (Table 2), aluminum wire and aluminum-alloy wire- by an average of $2-2.5 \%$ by reducing the number of passes (restringing of the straight -through drawing machine (SThDM) was carried out along the drawing route, calculated according to the proposed method). As a result of the study, a decrease in the effect of deformation fractionality was obtained and, accordingly, an improvement in the microstructure of copper. The recalculation of the standard drawing route for the smaller number of passes made it possible to exclude from the technology both two unused pulling units (PU) in the straight -through drawing machine and imported, expensive technological tool - dies. Thus, for SThDM with an individual electric drive (ED) for each pulling unit of straight -through drawing machines, in addition to improving the quality of the produced wire $[9,15]$, an energy-saving effect was also obtained (Table 2).

Table -2. Comparative analysis of the parameters of the drawing process [9].

\begin{tabular}{|c|c|c|c|c|}
\hline \multirow{2}{*}{ Parameters of drawing proccess } & \multicolumn{2}{|c|}{ General ED for DM } & \multicolumn{2}{|c|}{ Individual ED for every PU } \\
\hline & Operating & Rated & Operating & Rated \\
\hline 1 & 2 & 3 & 4 & 5 \\
\hline Number of passes, pcs & 10 & 6 & 7 & 5 \\
\hline Number of electric motors & \multicolumn{2}{|c|}{1} & 7 & 5 \\
\hline Power consumption, kW & \multicolumn{2}{|c|}{252} & 45 & 33,2 \\
\hline Material & \multicolumn{4}{|c|}{ Copper } \\
\hline Drawn product & \multicolumn{2}{|c|}{ Round wire } & \multicolumn{2}{|c|}{ Round wire } \\
\hline
\end{tabular}

Obtained results of the calculation, supported by the results of the industrial experiment, confirmed the correctness and adequacy of the proposed method of recalculation and optimization of the drawing route [9, 15] and as a consequence, the justification for the decision to disable the electric motors of pulling units of the straight -through drawing machine, which were not involved in the proposed route. A similar industrial experiment was conducted for a drawing machine with a main electric drive (type VSK -13). However, positive results were obtained only in terms of improving the quality parameters of samples of drawn copper wire (decrease in ohmic resistance), in terms of increasing the energy efficiency of the process for this particular type of DM - the energy parameters remained unchanged, since the considered DM had one main drive, which was kinematically connected with all the pulling drums, and therefore changing the route to a given outlet diameter was reduced to changing the number of inserted pulling washers [9-14].

\section{Conclusion}

It should be noted that reducing of the cable ohmic resistance will not only increase the cable performance, but will also reduce chosen core section, which will reduce eventually significantly the price of the cable line as a whole [15-19].

Proposed technical solution, presented in this article, is focused on the technological operation - drawing and allows, by making changes to the standard drawing route, a decrease in the ohmic resistance of the conductive core by $3-5 \%$ for copper and aluminum, respectively, which has a positive effect on reducing the operating temperature of the conductive part of the cable and will increase the reliability of the cable line as a whole.

\section{References}

1. Intellectual development of the electric power industry with the participation of an active consumer / Ed. by Bushuyev V.V. M.: Energy, 2013. 84 p. 
2. Bushuyev V.V., Kucherov Yu.N. Innovative development of the electric power industry as the most important priority of Russia's strategic development // Electro. № 1, 2016.

3. Yu.N. Kucherov, A.V. Ivanov, D.A. Korev, N.A. Utkin, A.S. Zhuk 1 Development of active consumer technologies and their integration into the public electricity network // Digital energy http://www.energystrategy.ru/DP/Source/DE_ 03.pd $\underline{f}$

4. Kucherov Yu.N., Berezovsky P.K., Veselov F.V., Ilyushin P.V. Analysis of general technical requirements for distributed generation facilities during their integration into the power system // Electric stations, № 3, 2016. p. 2-10

5. Ways to increase CL performance with insulation from cross-linked polyethylene https://mobile.ruscable.ru/article/212/

6. Increase in performance and operation of the cable line.

http://www.energomet-e.ru/news/kabel-s-izolazieyspe.

7. Nawalikhina E.Yu., Trufanova N.M. Computer model of heat and mass transfer processes in a cable channel under various operating modes of cable lines // Science Journal « Fundamental research », 2014. -№ 9 (Part 5)- p. 988-992

8. Pirmatov N.B., Ivanova V.P., Madrakhimov D.B. Improving energy efficiency of drawing equipment through energy and resources saving // International journal of advanced research in science, Engineering and technology, vol. 6, issue 3, March 2019.

9. Ivanova V.P. Improving power and resource savings of straight -through drawing machines. $\mathrm{PhD}$ Dissertation in Engineering Science, Tashkent 2020.

10. Vega G., Haddi A., Imad A., Temperature effects on wire-drawing process: experimental investigation // Int J Mater Form, 2009 - V. 2, №1. - P. $229-232$.

11. Muskalski Z., S. Wiewiórowska The theoretical analysis of wire drawing process for hydrodynamic friction conditions // Metallurgical and mining industry, 2011 - V. 3, № 7. - P. $74-78$.

12. Lo, S. Wire drawing dies with prescribed variations of strain rate / S. Lo, Y. Lu // Journal of Materials Processing Technology, 2001 - P. $212-218$
13. Berin I.Sh., Dnestrovsky N.Z. Copper and aluminium wire production, Metallurgy Publishing House. Moscow, 1974. p. 16-17, 19-22, 22-26.

14. Doshchinsky G.A., Sitnikova N.V. Determination of the magnitude of the Bauschinger effect with an increase in the degree of plastic deformation. Bulletin of the Tomsk Polytechnic Institute, 1976, p. 24-27.

15. Tsypkina V.V., Ivanova V.P. Рaзp Development of generalized requirements for the modernization of electric drive of drawing machines for cable production // Journal «Universum: Technical Sciences », - Moscow, 2017. -p.102-107.

16. Kaniskin V.A., Kostenko E.M.., Tadjibayev A.I. Non-destructive method for determining the service life of electric cables with polymer insulation under operating conditions // Electricity. 1995, № 5, p. 1923.

17. Larina E.T. Power cables and high-voltage cable lines. - second edition revised and supplemented, M.: Energoatomizdat, 1996, 464 p.

18. Hoshimov, F.A., Bakhadirov, I.I., Erejepov, M., Djumamuratov, B. (2019) Development of method for normalizing electricity consumption E3S Web Conf 139 doi:10.1051/e3sconf/201913901074

19. Nazarychev A.N., Andreev D.A., Tadjibayev A.I, Kasakov A.N. Calculation of technical resource of high-voltage cables with PVC insulation and XLPE insulation, taking into account operating conditions. Methodological issues in the study of the reliability of large energy systems, International Scientific Seminar, named after Yu.N. Rudenko, Issue 61 Problems of Research and Ensuring Reliability of Liberalized Energy Systems, 2018, Irkutsk, p. 1523

20. V. Ivanova, D. Madrakhimov. Direct flow drawing equipment performance reliability and increase of its effectiveness.

https://doi.org/10.1051/e3sconf/201913901 057

21. V. Tsipkia, V. Ivanova. Modeling of a resourcesaving method of drawing. https://doi.org/10.1051/e3sconf/201913901073 